\title{
Polymorphisms Associated with Both Noncardioembolic Stroke and Coronary Heart Disease: Vienna Stroke Registry
}

\author{
May M. Luke ${ }^{a}$ Wolfgang Lalouschek ${ }^{b} \quad$ Charles M. Rowland ${ }^{a}$ \\ Joseph J. Catanese ${ }^{a}$ Joel I. Bolonick ${ }^{a}$ Nam D. Bui ${ }^{a} \quad$ Stefan Greisenegger ${ }^{c}$ \\ Georg Endler ${ }^{d}$ James J. Devlin ${ }^{a}$ Christine Mannhalter ${ }^{d}$ \\ ${ }^{a}$ Celera, Alameda, Calif., USA; ${ }^{b}$ Department of Neurology, Hospital Barmherzige Brueder, ${ }^{c}$ University Clinic of \\ Neurology and ${ }^{\mathrm{d}}$ Clinical Institute of Medical and Chemical Laboratory Diagnostics, Medical University Vienna, \\ Vienna, Austria
}

\section{Key Words}

Single nucleotide polymorphisms $\cdot$ Coronary heart

disease $\cdot$ Stroke $\cdot$ Risk factors $\cdot$ Genetics

\begin{abstract}
Noncardioembolic stroke and coronary heart disease (CHD) may share genetic predispositions. We tested the hypothesis that genetic variants which are associated with risk of $\mathrm{CHD}$ would also be associated with risk of noncardioembolic stroke in 562 cases from the Vienna Stroke Registry and 815 controls. We selected 6 gene variants that had been consistently associated with risk of CHD in 3 studies, including the Atherosclerosis Risk in Communities study, and found that 4 of these gene variants were also associated with risk of noncardioembolic stroke. The odds ratios for noncardioembolic stroke were 1.31 (90\% Cl 1.07-1.60) for rs3900940 in MYH15, 1.24 (90\% Cl 1.01-1.5) for rs20455 in KIF6, 1.21 (90\% Cl 0.991.49) for rs 1010 in $V A M P 8$, and $1.20(90 \% \mathrm{Cl} 0.95-1.50)$ for rs10757274 on chromosome 9p21.
\end{abstract}

Copyright ๑ 2009 S. Karger AG, Basel

M.M.L., C.M.R., J.J.C., J.I.B., N.D.B., and J.J.D. are current or former employees of Celera and have contributed to the study design, statistical analysis, interpretation of data, and writing of the manuscript.

\section{Introduction}

Stroke and coronary heart disease (CHD) share several common risk factors [1]. In particular, noncardioembolic stroke and CHD both involve atherosclerosis and thrombosis; thus, gene variants associated with $\mathrm{CHD}$ may also be associated with noncardioembolic stroke.

For this study, we investigated whether gene variants associated with CHD are also associated with noncardioembolic stroke. We selected 6 single nucleotide polymorphisms (SNPs) that had previously been reported to be associated with CHD in at least 3 studies: the Atherosclerosis Risk in Communities (ARIC) and 2 additional studies. These included 5 SNPs that we have previously described: rs3900940 in MYH15, rs20455 in KIF6, rs1010 in VAMP8, rs2298566 in SNX19, and rs7439293 in PALLD [2], as well as the rs10757274 SNP on chromosome 9p21 described by McPherson et al. [3]. We asked whether carriers of the CHD risk alleles of these 6 SNPs, compared with noncarriers, had increased risk of noncardioembolic stroke in a case-control study consisting of 562 noncardioembolic stroke patients of Vienna Stroke Registry (VSR) [4] and 815 healthy controls from the city of Vienna [5].

\section{KARGER}

Fax +4161306 1234 E-Mail karger@karger.ch www.karger.com

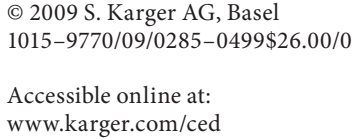

May M. Luke

Celera

1401 Harbor Bay Parkway

Alameda, CA 94502 (USA)

Tel. +1 510749 6267, Fax +1 510749 6200, E-Mail may.luke@celera.com 


\section{Subjects and Methods}

\section{Study Population}

The stroke cases in VSR are consecutive Caucasian patients admitted to stroke units in Vienna within $72 \mathrm{~h}$ of onset of acute ischemic stroke between October 1998 and June 2001 [4]. Only patients with noncardioembolic stroke (defined as ischemic stroke that was not of cardioembolic origin) were included as cases in this study since cardioembolic stroke involves distinct disease mechanisms, such as atrial fibrillation or heart valve disease, which are not common mechanisms of noncardioembolic stroke or CHD [6, 7]. In addition, there is evidence that some genetic variants may be associated with specific stroke subtypes [8, 9]. Controls were unrelated Caucasian participants in a health care program in Vienna, 45 years old or older, free of arterial vascular disease, and reported no arterial vascular diseases in first-degree relatives [5]. Genotypes were determined as described previously [10]. This study complied with the Declaration of Helsinki and was approved by the Ethics Committee of Medical University Vienna. All subjects gave written informed consent.

\section{Statistics}

Differences in traditional risk factors between cases and controls were assessed by the Wilcoxon rank-sum test for continuous variables or by the $\chi^{2}$ test for discrete variables. Odds ratios (OR) for the risk of noncardioembolic stroke for carriers of the CHD risk allele, compared with noncarriers, were estimated from logistic regression models and were adjusted for age (at the index stroke event for cases, at enrollment for controls), sex, current smoker (vs. not), diabetes (defined by a physician's diagnosis or the use of either insulin or oral hypoglycemic medications), hypertension (defined by systolic blood pressure $>140 \mathrm{~mm} \mathrm{Hg}$, diastolic blood pressure $>90 \mathrm{~mm} \mathrm{Hg}$, a physician's diagnosis of hypertension, or the use of anti-hypertensive medications), dyslipidemia [defined by a total cholesterol $\geq 240 \mathrm{mg} / \mathrm{dl}(6.2 \mathrm{mmol} / \mathrm{l})$, LDL-C $\geq 160 \mathrm{mg} /$ dl $(4.1 \mathrm{mmol} / \mathrm{l}), \mathrm{HDL}-\mathrm{C}<40 \mathrm{mg} / \mathrm{dl}(1.0 \mathrm{mmol} / \mathrm{l})$, or the use of lipid lowering medications], and body mass index (BMI). Since this study tested whether the allele associated with increased CHD risk was also associated with increased risk of noncardioembolic stroke, and we would not have considered any association of the opposite direction (e.g. between noncardioembolic stroke and the CHD nonrisk allele) to be significant, we used one-sided p values and $90 \%$ CI to assess the significance of the genetic associations. To account for multiple hypothesis testing, the false discovery rate $q$ values were estimated by the method of Benjamini and Hochberg [11] using the $p$ values for carriers of the risk allele from the age- and sex-adjusted model (model 1 , table 1). The $q$ value of a given SNP represents the expected proportion of false-positives among the set of SNPs with equal or lower $q$ values. We used Quanto 1.1 (http://hydra.usc.edu/gxe) to calculate the effect sizes of noncardioembolic stroke risk (for carriers of the risk alleles, compared with noncarriers) that would be detectable with $90 \%$ power assuming a one-sided test and a significance level of 0.05 .

To explore whether population stratification may have confounded our results, we used a Bayesian clustering approach with the Structure software [12] and the genotypes of 130 SNPs (minor allele frequencies ranged from 0.95 to $49.8 \%$ ) to evaluate models that assumed 1, 2, 3, or 4 distinct ancestral populations among our study population. We found that a model assuming 2 ancestral populations resulted in the highest estimated log likelihood.
Using the 2 ancestral population model, we estimated the fraction of the 2 ancestral populations in each individual subject. To adjust the risk estimates for population stratification, we included the fraction of the ancestral population as a covariate in logistic regression models.

\section{Results}

The clinical characteristics of the cases and controls are presented in table 2. We tested the hypothesis that 6 SNPs that had previously been associated with risk of CHD in at least 3 studies [2,3] were also associated with risk of noncardioembolic stroke in the Vienna Stroke Registry. Specifically, we tested if carriers of the CHD risk alleles of these 6 SNPs were also at increased risk of noncardioembolic stroke. The genotype distribution of these 6 SNPs did not deviate from Hardy-Weinberg equilibrium ( $\mathrm{p}>0.17)$.

We found that for 2 of these SNPs, carriers of the CHD risk allele, compared with noncarriers, had increased risk of noncardioembolic stroke after adjusting for age and sex: the ORs were 1.31 (CI 1.07-1.60) for the MYH15 SNP and 1.24 (CI 1.01-1.52) for the KIF6 SNP (table 1). To account for multiple testing (6 SNPs were tested), we estimated the false discovery rate [11]. We found that for the group of 4 SNPs with the lowest $p$ values, the false discovery rate was $15 \%$ (table 1), that is, we expect that on average, $15 \%$ of these 4 SNPs (i.e. less than 1 SNP) would be false-positives. In addition to the MYH15 and KIF6 SNPs, this group of 4 SNPs included 1 in VAMP8 and 1 on chromosome 9p21: the ORs for noncardioembolic stroke were 1.21 (CI 0.99-1.49) for the VAMP8 SNP and 1.20 (CI 0.951.50) for the 9p21 SNP (table 1). Although our prespecified analysis was a comparison of carriers versus noncarriers, on examination of the homozygous and heterozygous carriers separately, we found that for the 9p21 SNP only the homozygous carriers $(\mathrm{OR}=1.59)$ and not the heterozygous $(\mathrm{OR}=1.05)$ carriers were at increased risk of stroke. These ORs for noncardioembolic stroke for carriers of these 4 SNPs decreased somewhat after adjustment for additional risk factors (smoking, hypertension, diabetes, dyslipidemia, and BMI) with the exception of the OR for the VAMP8 carriers which increased (model 2 , table 1). To investigate whether the associations between stroke and these SNPs could have been confounded by myocardial infarction among the stroke cases, we repeated the analysis for association of the $6 \mathrm{CHD}$-associated SNPs with noncardioembolic stroke after excluding all cases with a history of myocardial infarction $(n=40)$. We found that excluding cases with a history of myocar- 
Table 1. Adjusted association of 6 SNPs with noncardioembolic stroke in VSR

\begin{tabular}{|c|c|c|c|c|c|c|c|}
\hline \multirow[t]{2}{*}{ SNP ID } & \multirow[t]{2}{*}{ Case $^{a}$} & \multirow[t]{2}{*}{ Control $^{\mathrm{a}}$} & \multicolumn{3}{|l|}{ Model 1} & \multicolumn{2}{|l|}{ Model 2} \\
\hline & & & OR and $90 \% \mathrm{CI}$ & $\mathrm{p}$ & $q^{\mathrm{b}}$ & OR and $90 \% \mathrm{CI}$ & $\mathrm{p}$ \\
\hline \multicolumn{8}{|c|}{ МYH15 rs3900940 } \\
\hline $\mathrm{CC}+\mathrm{CT}$ & $281(55.6)$ & $390(49.8)$ & $1.31(1.07-1.60)$ & 0.01 & 0.06 & $1.25(1.00-1.56)$ & 0.05 \\
\hline $\mathrm{CC}$ & $56(11.1)$ & $72(9.2)$ & $1.50(1.06-2.11)$ & 0.03 & & $1.19(0.80-1.75)$ & 0.24 \\
\hline $\mathrm{CT}$ & $225(44.5)$ & $318(40.6)$ & $1.27(1.03-1.56)$ & 0.03 & & $1.26(1.00-1.59)$ & 0.05 \\
\hline TT & $225(44.5)$ & $394(50.3)$ & ref. & & & ref. & \\
\hline \multicolumn{8}{|c|}{ KIF6 rs20455 } \\
\hline $\mathrm{GG}+\mathrm{GA}$ & $327(64.8)$ & $475(60.7)$ & $1.24(1.01-1.52)$ & 0.05 & 0.12 & $1.23(0.98-1.54)$ & 0.07 \\
\hline GG & $73(14.5)$ & $102(13.0)$ & $1.24(0.91-1.69)$ & 0.13 & & $1.30(0.93-1.83)$ & 0.10 \\
\hline GA & $254(50.3)$ & $373(47.7)$ & $1.24(1.00-1.53)$ & 0.05 & & $1.20(0.95-1.53)$ & 0.10 \\
\hline $\mathrm{AA}$ & $178(35.3)$ & $307(39.3)$ & ref. & & & ref. & \\
\hline \multicolumn{8}{|c|}{ VAMP8 rs1010 } \\
\hline $\mathrm{CC}+\mathrm{CT}$ & $326(64.4)$ & $483(61.6)$ & $1.21(0.99-1.49)$ & 0.06 & 0.12 & $1.33(1.06-1.67)$ & 0.02 \\
\hline $\mathrm{CC}$ & $77(15.2)$ & $112(14.3)$ & $1.27(0.93-1.72)$ & 0.10 & & $1.37(0.98-1.91)$ & 0.06 \\
\hline $\mathrm{CT}$ & $249(49.2)$ & $371(47.3)$ & $1.20(0.96-1.49)$ & 0.09 & & $1.32(1.04-1.68)$ & 0.03 \\
\hline TT & $180(35.6)$ & $301(38.4)$ & ref. & & & ref. & \\
\hline \multicolumn{8}{|c|}{$9 p 21$ rs10757274 } \\
\hline $\mathrm{GG}+\mathrm{GA}$ & $386(76.7)$ & $568(72.4)$ & $1.20(0.95-1.50)$ & 0.10 & 0.15 & $1.14(0.89-1.46)$ & 0.20 \\
\hline GG & $139(27.6)$ & $154(19.6)$ & $1.59(1.20-2.11)$ & 0.004 & & $1.45(1.06-1.98)$ & 0.03 \\
\hline GA & $247(49.1)$ & $414(52.8)$ & $1.05(0.82-1.34)$ & 0.38 & & $1.02(0.78-1.33)$ & 0.45 \\
\hline $\mathrm{AA}$ & $117(23.3)$ & $216(27.6)$ & ref. & & & ref. & \\
\hline \multicolumn{8}{|c|}{ SNX19 rs2298566 } \\
\hline $\mathrm{CC}+\mathrm{AC}$ & $473(94.5)$ & 744 (94.9) & $0.93(0.61-1.43)$ & 0.61 & 0.73 & $0.88(0.55-1.40)$ & 0.68 \\
\hline $\mathrm{CC}$ & $294(58.1)$ & $456(58.2)$ & $0.97(0.63-1.50)$ & 0.55 & & $0.95(0.59-1.53)$ & 0.57 \\
\hline $\mathrm{AC}$ & $179(35.4)$ & $288(36.7)$ & $0.87(0.56-1.37)$ & 0.69 & & $0.77(0.48-1.26)$ & 0.81 \\
\hline AA & $33(6.5)$ & $40(5.1)$ & ref. & & & ref. & \\
\hline \multicolumn{8}{|c|}{ PALLD rs7439293 } \\
\hline $\mathrm{AA}+\mathrm{GA}$ & $425(84.3)$ & $667(85.4)$ & $0.89(0.68-1.17)$ & 0.76 & 0.76 & $0.92(0.67-1.25)$ & 0.68 \\
\hline $\mathrm{AA}$ & $201(39.9)$ & $290(37.1)$ & $0.94(0.70-1.27)$ & 0.63 & & $1.02(0.73-1.42)$ & 0.46 \\
\hline GA & $224(44.4)$ & $377(48.3)$ & $0.85(0.63-1.14)$ & 0.83 & & $0.84(0.60-1.16)$ & 0.81 \\
\hline GG & $79(15.7)$ & $114(14.6)$ & ref. & & & ref. & \\
\hline
\end{tabular}

Model 1 was adjusted for age and sex. Model 2 was adjusted for age, sex, smoking, hypertension, diabetes, dyslipidemia, and BMI. Values in parentheses indicate percentages or $95 \%$ CI.

a Individuals with missing genotype or traditional risk factor information were excluded.

${ }^{\mathrm{b}}$ False discovery rate $q$ value.

dial infarction from the analysis did not appreciably change the fully adjusted ORs for the 9p21 homozygotes (1.45, CI 1.05-1.99), MYH15 carriers (1.24, CI 0.99-1.55), or VAMP8 carriers (1.28, CI 1.01-1.61). However, it did reduce the OR for KIF6 carriers to 1.15 (CI 0.91-1.45).

Since population stratification can confound analyses of case-control studies, we estimated the fraction of ancestral populations due to admixture in each subject and further adjusted the risk estimates of each SNP by the ancestry composition of the subjects. This adjustment did not appreciably change the risk estimates (the largest change was a decrease of 0.01 in the OR for 9p21 homozygotes).

\section{Discussion}

We tested the hypothesis that SNPs associated with CHD were associated with noncardioembolic stroke in VSR. When limiting the false discovery rate to $15 \%$, we 
Table 2. Characteristics of noncardioembolic stroke cases and healthy controls

\begin{tabular}{lccc}
\hline Characteristics & $\begin{array}{l}\text { Cases } \\
(\mathrm{n}=562)\end{array}$ & $\begin{array}{l}\text { Controls } \\
(\mathrm{n}=815)\end{array}$ & $\mathrm{p}$ \\
\hline Age, years & $66.0 \pm 14$ & $58.8 \pm 8.5$ & $<0.0001$ \\
Male & $326(58.0)$ & $397(48.7)$ & 0.0007 \\
Smoking & $172(32.0)$ & $147(18.7)$ & $<0.0001$ \\
Hypertension & $400(71.2)$ & $403(49.5)$ & $<0.0001$ \\
Diabetes & $191(34.0)$ & $36(4.4)$ & $<0.0001$ \\
Dyslipidemia & $347(61.7)$ & $464(56.9)$ & 0.07 \\
BMI & $26.8 \pm 4.9$ & $26.0 \pm 3.8$ & 0.004 \\
\hline
\end{tabular}

Age and BMI are presented as means \pm SD. Figures in parentheses are percentages.

found that carriers of the CHD risk allele for 4 of the 6 SNPs we tested also had increased risk of noncardioembolic stroke. Three of these 4 SNPs were in the genes MYH15 (rs3900940), KIF6 (rs20455), VAMP8 (rs1010), and the remaining SNP was on chromosome 9p21 (rs10757274).

Many genetic associations of stroke, a common complex disease, have been reported, but few have been consistently replicated. Pruissen et al. [13] discussed several reasons for the failure to replicate results from the initial association studies, these include small sample sizes, inappropriate (either inadequate or overly conservative) correction for multiple testing, population stratification, phenotype heterogeneity, and different study designs. This study has addressed several of these issues: it used a sample size of 562 cases and 814 controls, corrected for multiple testing using the false discovery rate method, adjusted for potential population stratification, and used only the noncardioembolic stroke as the end point.

The MYH15 rs3900940 SNP that showed an association with noncardioembolic stroke in the current study also showed a consistent association with incident ischemic stroke in ARIC and in the Cardiovascular Health Study (CHS). The hazard ratios for carrying each of the risk alleles among white participants were 1.18 in ARIC ( $\mathrm{p}=0.08$, appendix 1 in Morrison et al. [14]) and 1.15 in CHS ( $\mathrm{p}=0.033$, table 1 in Luke et al. [15]). MYH15 encodes myosin heavy polypeptide 15, and the rs3900940 SNP, corresponding to an amino acid change at Thr1125Ala, is located in the coiled-coil rod domain of the MYH15 protein. The Thr1125 residue has been shown to be phosphorylated $[16,17]$. Since the Ala1125 residue can not be phosphorylated, this substitution may affect the function of the MYH15 protein that is regulated by phosphorylation.

The VAMP8 rs1010 SNP has also been tested in ARIC and CHS for association with incident ischemic stroke. The risk estimate for the $\mathrm{C}$ allele in white participants of ARIC was consistent with results in the current study: the hazard ratio was 1.16 for each C allele ( $\mathrm{p}=0.10$, appendix 1 in Morrison et al. [14]). However, the VAMP8 SNP was not associated with incident ischemic stroke in CHS ( $\mathrm{p}=$ 0.63 , online table in Luke et al. [15]).

The SNP rs10757274 on chromosome 9p21 had been reported both to be associated [18] as well as not to be associated $[19,20]$ with ischemic stroke. Another chromosome 9p21 SNP, rs10757278, which is associated with myocardial infarction and is in linkage disequilibrium with $\mathrm{rs} 10757274\left(\mathrm{r}^{2}=0.89\right)$, was reported to be associated with a combined end point of large artery atherosclerotic and cardiogenic stroke [21] but not to be associated with ischemic stroke [22]. Most recently, several 9p21 SNPs were tested for association with ischemic stroke and its subtypes, cardioembolic stroke, atherosclerotic stroke, and small vessel stroke. A number of these were found to be associated only with the atherosclerotic stroke subtype [23]. Our result showed rs 10757274 to be associated with noncardioembolic stroke, but since the case definition we used was different from those in the previous reports, our result does not resolve the apparent contradicting observations in the current literature.

The rs20455 SNP in KIF6 was not associated with incident ischemic stroke in ARIC [14] or in CHS [15]. The association of this SNP with noncardioembolic stroke in this study could have been confounded by the presence of CHD in some of the stroke cases. This notion is consistent with the observation that the OR for noncardioembolic stroke was attenuated when cases with a history of myocardial infarction were excluded from the analysis.

We did not find an association of the PALLD or SNX19 SNP with noncardioembolic stroke in this study. This study provided $90 \%$ power to detect an association between carrier status and noncardioembolic stroke if the risk ratio in the population was 1.70 for the PALLD SNP or 2.50 for the SNX19 SNP. Thus, these 2 SNPs may not be associated with noncardioembolic stroke, or this study did not provide sufficient power to detect the associations with lower risk ratios.

Potential limitations of this study include the casecontrol study design; these results may have been affected by survival bias and do not account for effects on stroke risk due to various drug treatments prior to the index event of cases or to the enrollment date of the controls. 
This study included only Caucasian subjects; therefore, these SNPs should be tested in other populations.

In conclusion, we found that carriers of the CHD risk allele of 4 SNPs also had increased risk of noncardioembolic stroke in VSR, and these SNPs merit further testing in additional stroke studies.

\section{Appendix}

Two-Sided Statistical Test. A statistical test in which the null hypothesis is rejected for values of the test statistics falling into either tail of its sampling distribution.

One-Sided Statistical Test. A statistical test in which the null hypothesis is rejected only for values of the test statistics falling into 1 specified tail of its sampling distribution.

Multiple Testing. A statistical problem that occurs when one simultaneously considers multiple comparisons or tests multiple hypotheses. This is a problem because the probability of rejecting 1 or more null hypotheses incorrectly by chance is increased.

False Discovery Rate. A statistical method used to estimate the proportion of hypotheses that are falsely declared significant when multiple hypotheses are tested. The false discovery rate is also the expected proportion of rejected null hypotheses that are incorrectly rejected (false-positives). $q$ Value. The minimum false discovery rate at which a test may be declared significant.

Population Stratification. This manifests in genetic studies as the presence of differences in allele frequencies among subpopulations within a population, possibly due to subpopulations of different ancestry or due to admixed populations where individuals may have mixed ancestry. When population stratification exists and disease prevalence varies by subpopulations or by ancestry composition, spurious associations between disease and a genetic marker may occur. Specifically, any allele that is more frequent among the subpopulation having the higher prevalence of disease will be associated with disease status.

\section{Sources of Funding}

The VSR was supported by grants from the Medizinisch-Wissenschaftlicher Fonds des Bürgermeisters der Bundeshauptstadt Wien (project numbers 1540, 1829, 1970), the Jubiläumsfonds der Oesterreichischen Nationalbank (project numbers 6866, 7115, 8281,9344), and the Austrian Science Foundation (P13902-MED) and from the Wiener Krankenanstaltenverbund. This work was supported in part by Jubiläumsfonds der Österreichischen Nationalbank No. 9344

\section{References}

1 Rosamond W, Flegal K, Furie K, Go A, Greenlund K, Haase N, Hailpern SM, Ho M, Howard V, Kissela B, Kittner S, Lloyd-Jones D, McDermott M, Meigs J, Moy C, Nichol G, O’Donnell C, Roger V, Sorlie P, Steinberger J, Thom T, Wilson M, Hong Y: Heart disease and stroke statistics - 2008 update: a report from the American Heart Association Statistics Committee and Stroke Statistics Subcommittee. Circulation 2008;117:e25-e146.

2 Bare LA, Morrison AC, Rowland CM, Shiffman D, Luke MM, Iakoubova OA, Kane JP, Malloy MJ, Ellis SG, Pankow JS, Willerson JT, Devlin JJ, Boerwinkle E: Five common gene variants identify elevated genetic risk for coronary heart disease. Genet Med 2007; 9:682-689.

- 3 McPherson R, Pertsemlidis A, Kavaslar N, Stewart A, Roberts R, Cox DR, Hinds DA, Pennacchio LA, Tybjaerg-Hansen A, Folsom AR, Boerwinkle E, Hobbs HH, Cohen JC: A common allele on chromosome 9 associated with coronary heart disease. Science 2007; 316:1488-1491.

4 Lang W: The Vienna Stroke Registry - objectives and methodology. The Vienna Stroke Study Group. Wien Klin Wochenschr 2001; 113:141-147.

5 Lalouschek W, Lang W, Mullner M: Current strategies of secondary prevention after a cerebrovascular event: the Vienna stroke registry. Stroke 2001;32:2860-2866.
6 Amarenco P, Bogousslavsky J, Caplan LR, Donnan GA, Hennerici MG: Classification of stroke subtypes. Cerebrovasc Dis 2009;27: 493-501.

-7 Amarenco P, Bogousslavsky J, Caplan LR, Donnan GA, Hennerici MG: New approach to stroke subtyping: The A-S-C-O (phenotypic) classification of stroke. Cerebrovasc Dis 2009;27:502-508.

-8 Fatar M, Stroick M, Steffens M, Senn E, Reuter B, Bukow S, Griebe M, Alonso A, Lichtner $\mathrm{P}$, Bugert $\mathrm{P}$, Meitinger T, Wienker TF, Hennerici MG: Single-nucleotide polymorphisms of MMP-2 gene in stroke subtypes. Cerebrovasc Dis 2008;26:113-119.

-9 Rao R, Tah V, Casas JP, Hingorani A, Whittaker J, Smeeth L, Sharma P: Ischaemic stroke subtypes and their genetic basis: a comprehensive meta-analysis of small and large vessel stroke. Eur Neurol 2009;61:7686.

10 Shiffman D, Ellis SG, Rowland CM, Malloy MJ, Luke MM, Iakoubova OA, Pullinger CR, Cassano J, Aouizerat BE, Fenwick RG, Reitz RE, Catanese JJ, Leong DU, Zellner C, Sninsky JJ, Topol EJ, Devlin JJ, Kane JP: Identification of four gene variants associated with myocardial infarction. Am J Hum Genet 2005;77:596-605.
11 Benjamini Y, Hochberg Y: Controlling the false discovery rate: a new and powerful approach to multiple testing. J Royal Stat Soc Series B Stat Methodol 1995;57:289-300.

12 Pritchard JK, Stephens M, Donnelly P: Inference of population structure using multilocus genotype data. Genetics 2000;155:945959.

$\checkmark 13$ Pruissen DM, Kappelle LJ, Rosendaal FR, Algra A: Genetic association studies in ischaemic stroke: replication failure and prospects. Cerebrovasc Dis 2009;27:290-294.

14 Morrison AC, Bare LA, Luke MM, Pankow JS, Mosley TH, Devlin JJ, Willerson JT, Boerwinkle E: Single nucleotide polymorphisms associated with coronary heart disease predict incident ischemic stroke in the atherosclerosis risk in communities study. Cerebrovasc Dis 2008;26:420-424.

15 Luke MM, O’Meara ES, Rowland CM, Shiffman D, Bare LA, Arellano AR, Longstreth WT Jr, Lumley T, Rice K, Tracy RP, Devlin JJ, Psaty BM: Gene variants associated with ischemic stroke. The Cardiovascular Health Study. Stroke 2009;40:363-368.

16 Gnad F, Ren S, Cox J, Olsen JV, Macek B, Oroshi M, Mann M: PHOSIDA (phosphorylation site database): management, structural and evolutionary investigation, and prediction of phosphosites. Genome Biol 2007; $8: R 250$. 
-17 Olsen JV, Blagoev B, Gnad F, Macek B, Kumar C, Mortensen P, Mann M: Global, in vivo, and site-specific phosphorylation dynamics in signaling networks. Cell 2006;127: 635-648.

-18 Smith JG, Melander O, Lovkvist H, Hedblad B, Engstrom G, Nilsson P, Carlson J, Berglund G, Norrving B, Lindgren A: Common genetic variants on chromosome 9p21 confers risk of ischemic stroke: a large-scale genetic association study. Circ Cardiovasc Genet 2009;2:159-164.

19 Zee RY, Ridker PM: Two common gene variants on chromosome 9 and risk of atherothrombosis. Stroke 2007;38:e111.

-20 Yamagishi K, Folsom AR, Rosamond WD, Boerwinkle E: A genetic variant on chromosome 9p21 and incident heart failure in the ARIC study. Eur Heart J 2009;30:12221228 .
21 Helgadottir A, Thorleifsson G, Magnusson KP, Gretarsdottir S, Steinthorsdottir V, Manolescu A, Jones GT, Rinkel GJ, Blankensteijn JD, Ronkainen A, Jaaskelainen JE, Kyo Y, Lenk GM, Sakalihasan N, Kostulas K, Gottsater A, Flex A, Stefansson H, Hansen T, Andersen G, Weinsheimer S, Borch-Johnsen K, Jorgensen T, Shah SH, Quyyumi AA, Granger CB, Reilly MP, Austin H, Levey AI, Vaccarino V, Palsdottir E, Walters GB, Jonsdottir T, Snorradottir S, Magnusdottir D, Gudmundsson G, Ferrell RE, Sveinbjornsdottir S, Hernesniemi J, Niemela M, Limet R, Andersen K, Sigurdsson G, Benediktsson R, Verhoeven EL, Teijink JA, Grobbee DE, Rader DJ, Collier DA, Pedersen O, Pola R, Hillert J, Lindblad B, Valdimarsson EM, Magnadottir HB, Wijmenga C, Tromp G, Baas AF, Ruigrok YM, van Rij AM, Kuivaniemi H, Powell JT, Matthiasson SE, Gulcher JR, Thorgeirsson G, Kong A, Thorsteinsdottir $\mathrm{U}$, Stefansson K: The same sequence variant on 9p21 associates with myocardial infarction, abdominal aortic aneurysm and intracranial aneurysm. Nat Genet 2008;40:217224.
22 Lemmens R, Abboud S, Robberecht W, Vanhees L, Pandolfo M, Thijs V, Goris A: Variant on 9p21 strongly associates with coronary heart disease, but lacks association with common stroke. Eur J Hum Genet 2009, E-pub ahead of print.

23 Gschwendtner A, Bevan S, Cole JW, Plourde A, Matarin M, Ross-Adams H, Meitinger T, Wichmann E, Mitchell BD, Furie K, Slowik A, Rich SS, Syme PD, MacLeod MJ, Meschia JF, Rosand J, Kittner SJ, Markus HS, MullerMyhsok B, Dichgans M: Sequence variants on chromosome 9p21.3 confer risk for atherosclerotic stroke. Ann Neurol 2009;65: 531-539. 